\title{
VULNERABILIDADE E INCIDÊNCIA DA COVID-19 NO NORDESTE DO BRASIL ATRAVÉS DA ANÁLISE DE CLUSTER
}

\section{VULNERABILITY AND INCIDENCE OF COVID-19 IN NORTHEASTREGION OF BRAZIL THROUGH OF THE CLUSTER ANALYSIS}

\author{
Marcelo Luís de Amorim Souza \\ Doutor em Ciências Climáticas (UFRN) \\ Instituto Federal do Rio Grande do Norte (IFRN) campus São Gonçalo do Amarante \\ marcelo.amorim@ifrn.edu.br \\ Thiago Valentim Marques \\ Doutor em Ciências Climáticas (UFRN) \\ Instituto Federal do Rio Grande do Norte (IFRN) campus Natal-Zona Norte \\ thiago.valentim@ifrn.edu.br \\ Maria Marla Paiva de Amorim \\ Especialista em Enfermagem e Terapia Intensiva (UnP) \\ Hospital Universitário Onofre Lopes (HUOL) - EBSERH \\ maria.paiva@ebserh.gov.br
}

\begin{abstract}
RESUMO
A COVID-19 tornou-se uma epidemia em proporção global. A maior susceptibilidade de disseminação da doença e da mortalidade relaciona-se a fatores sociodemográficos e a morbidades crônicas subjacentes. A doença tem apresentado grande impacto social e econômico, afetando diretamente à saúde das pessoas e, consequentemente, o mundo do trabalho. Objetivou-se criar perfis de vulnerabilidade demográfica e de morbidade à incidência da COVID-19 para os municípios do Nordeste do Brasil (NEB). Os dados são do IBGE e do Ministério da saúde, e as variáveis são: densidade demográfica, taxa de urbanização, percentual de idosos acima de 60 anos e internações hospitalares de 2015 a 2019 - Tuberculose, AIDS, Diabetes, Obesidade e Asma. Utilizou-se a análise de cluster, com objetivo de identificar padrões de similaridade entre os municípios do NEB. A vulnerabilidade é apresentada em quatro clusters: baixa, moderada, alta e crítica. Observouse uma heterogeneidade na distribuição dos clusters com alta e crítica vulnerabilidades nas capitais, exceto Aracaju (SE). A maioria dos municípios polos de cada estado apresentou vulnerabilidade moderada. A "vulnerabilidade crítica" apresentou alta densidade demográfica, alta taxa de urbanização, alto percentual de idosos acima de 60 anos e alto número de internações de pessoas com asma, obesidades, AIDS, tuberculose e diabetes. A "vulnerabilidade baixa" foi constituída, em sua maioria, por municípios com baixa densidade demográfica, baixa urbanização e baixo número de internações correspondentes às doenças selecionadas, sendo o percentual de idosos acima de 60 anos o segundo maior. Os resultados poderão contribuir para refletir sobre políticas públicas de combate a surtos e de proteção social.
\end{abstract}

Palavras-chave: SARS. Coronavírus. Síndrome respiratória. Morbidade. Socioeconômico.

\begin{abstract}
COVID-19 has become an epidemic of global proportion. The increased susceptibility to the spread of the disease and mortality is related to sociodemographic factors and underlying chronic morbidities. The disease has a great social and economic impact directly affecting people's health and, consequently, the world of the work. The objective of this study was to create profiles of demographic vulnerability and morbidity to the incidence of COVID-19 for municipalities in northeastern Brazil (NEB). The data are from IBGE and Ministry of Health and the variables are: demographic density, urbanization rate, percentage of elderly over 60 years and hospitalizations from 2015 to 2019 - Tuberculosis, AIDS, Diabetes, Obesity and Asthma. Cluster analysis was used to identify similarity patterns between NEB municipalities. The vulnerability is presented in four clusters: low, moderate, high, and critical. Heterogeneity
\end{abstract}

Recebido em: 23/06/2020

Aceito para publicação em: 06/08/2020. 


\begin{abstract}
was observed in the distribution of clusters with high and critical vulnerabilities in the capitals, except Aracaju (SE). Most of the municipalities in each state presented moderate vulnerability. The "critical vulnerability" presented high demographic density, high urbanization rate, high percentage of elderly over 60 years and high number of hospitalizations of people with asthma, obesity, AIDS, tuberculosis and diabetes. The "low vulnerability" was constituted, mostly, by municipalities with low population density, low urbanization and low number of hospitalizations corresponding to the selected diseases, with the percentage of elderly over 60 years being the second highest. The results may contribute to reflect on public policies to combat outbreaks and social protection.
\end{abstract}

Keywords: SARS. Coronavirus. Respiratory syndrome. Morbidity. Socioeconomic.

\title{
INTRODUÇÃO
}

O mundo tem acompanhado, desde dezembro de 2019, o início de um surto epidemiológico que ocorreu inicialmente em Wuhan, província de Hubei na China (LU et al., 2020). Porém, há indícios de que o vírus SARS-Cov-2, que provoca a COVID-19, circulava no território chinês desde o mês de novembro de 2019 (DELATORRE et al., 2020). Para Xu et al. (2004), a China já havia passado por outro surto epidêmico em 2002, denominada de Síndrome Respiratória Aguda Grave (SARS), causado pelo vírus SARS-CoV. Mesmo sendo as duas síndromes respiratórias semelhantes, Liu et al. (2020) afirmam que a COVID-19 é de maior transmissão, mesmo considerando uma maior conscientização pública e havendo respostas intervencionistas governamentais.

A COVID-19 espalhou-se rapidamente em território chinês, tornando-se uma epidemia em proporção global, uma pandemia (EMANI et al., 2020). Segundo a Organização Mundial da Saúde - OMS (WHO, 2020), até o dia 05.08.2020, eram mais de 18,31 milhões de casos confirmados e 695.043 óbitos em 216 países, áreas ou territórios. No Brasil, o Ministério da Saúde, em 04.08.2020, registrava mais de 2.801.921 casos confirmados e 95.819 óbitos (BRASIL, 2020a). Para Ahmed et al. (2020), a maior probabilidade de casos e óbitos associada à COVID-19 está nas populações mais pobres, devido a suas condições econômicas, sociais e sanitárias.

Conforme o Ministério da Saúde (BRASIL, 2020), a COVID-19 se manifesta com quadros clínicos que variam de infecções assintomáticas a quadros graves, em que $20 \%$ dos infectados necessitam de atendimento hospitalar, e $5 \%$ destes podem precisar de ventilação artificial. A doença tem se apresentado com grande capacidade de impacto social e econômico, afetando a saúde física e mental das pessoas como também o mundo do trabalho. Com relação ao "mundo do trabalho", há dados dos quais apontam que cada redução de um ponto percentual na economia global pode acarretar a inclusão de mais de 10 milhões de pessoas na pobreza (AHMED et al., 2020), o que poderá agravar o combate à pandemia e seus efeitos sociais e econômicos, a médio e longo prazo. Além disso, afirma-se que o custo da COVID-19 (além das vidas perdidas) ao mundo pode superar os 10 trilhões de dólares (AHMED et al., 2020).

Sabe-se que as condições do clima frio e seco podem possibilitar a proliferação do vírus e da COVID19 (SUN et al, 2020), porém a disseminação no Brasil, onde predomina um clima quente e úmido, coloca em evidência a importância de outros fatores. Os fatores sociais, isto é, as desigualdades sociais, são pontos ou condições das dificuldades de combate à Covid-19, a partir do uso de estratégias simples: lavar as mãos (quando não se tem água encanada o dia todo); populações sem renda ou com baixa remuneração (para comprar álcool em gel); e aglomeração de pessoas em uma casa pequena (com um único banheiro). Fatores demográficos e epidemiológicos também podem favorecer a um maior risco: pessoas de mais idade e com morbidades crônicas são mais vulneráveis (CHEN et al., 2020; WILKISON et al., 2020). Dentre as comorbidades subjacentes, temos: doenças pulmonares crônicas, asma, problemas cardíacos, deficiências imunológicas (AIDS), obesidade, diabetes, doença renal crônica e doença hepática (CDC, 2020, WILKISON et al., 2020).

Dentre as condições de propagação, os casos e óbitos da região Nordeste vêm sendo susbstancialmente afetados pela Covid-19 que, segundo o Ministério da Saúde (BRASIL, 2020a) em 04.08.2020, somavam 894.639 casos confirmados e 29.644 óbitos. Este artigo tem como objetivo criar perfis de vulnerabilidade demográfica e de morbidade à incidência da COVID-19 para os municípios do Nordeste do Brasil (NEB). Tal análise pode contribuir para direcionar propostas de construção de um observatório da Covid-19, políticas públicas (federais, estaduais e municipais) de combate a surtos e 
políticas sociais de segurança e proteção social em áreas urbanas e rurais, em que as pessoas sofrem carências de diversas ordens do poder público.

\section{MATERIAL E MÉTODOS}

A pesquisa realizada é do tipo exploratório-descritivo, com delineamento ecológico de dados agregados e abordagem quantitativa. Os dados utilizados para a análise não permitem a identificação dos pacientes internados.

\section{Área de Estudo}

O Nordeste do Brasil (NEB) está situado, aproximadamente, entre as latitudes de $1^{\circ} \mathrm{N}$ e $18,5^{\circ} \mathrm{S}$ e as longitudes de $34,5^{\circ} \mathrm{W}$ e $48,5^{\circ} \mathrm{W}$ e ocupa uma posição de extrema importância em função de sua proximidade com os continentes africano e europeu. A região é composta por nove estados da Federação, distribuídos em 1.794 municípios (Figura 1), cuja extensão territorial é próxima da soma dos territórios da Espanha, França, Itália e Japão. A população estimada do NEB, em 2019, era de 57.071.654 de habitantes (IBGE, 2019).

Figura 1 - Região Nordeste com localização e divisão estadual e municipal

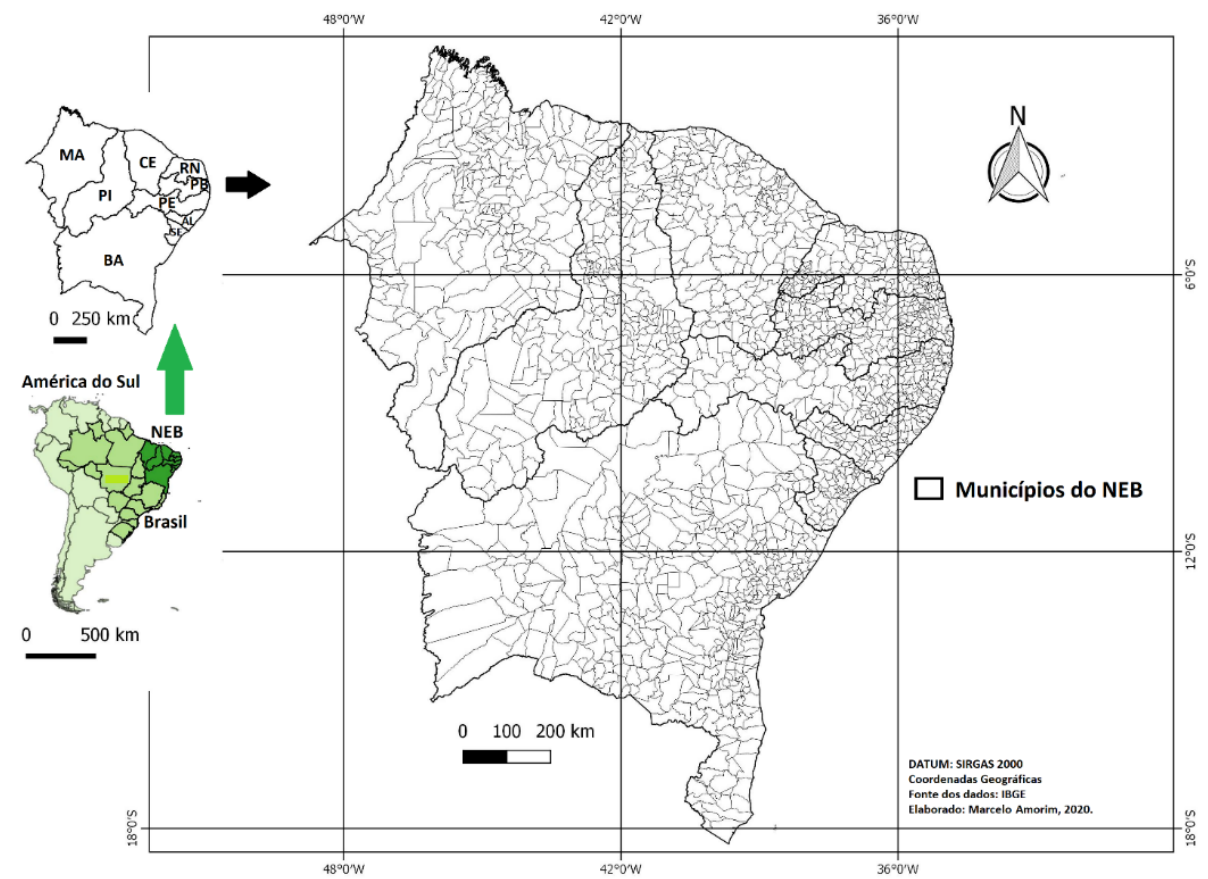

Fonte: Elaborado pelos autores

\section{Dados}

Os dados utilizados na pesquisa foram demográficos e de morbidades. Foram utilizados os softwares Action Stat (versão 3.6) e $R$ (versão 3.6.3), para a análise da estatística descritiva, e criação dos clusters e o QGIS (versão 3.10), para a elaboração dos mapas.

\section{Dados Demográficos}

As variáveis demográficas utilizadas referem-se à densidade demográfica, taxa de urbanização e percentual de idosos acima de 60 anos. A escolha dessas variáveis baseia-se na suposição de que elas podem estar associadas a uma maior facilitação da propagação do vírus e ao processo de interiorização da COVID-19 pelo território nordestino. Foram utilizadas informações do Censo Demográfico (2010) e da estimativa populacional (2019) do IBGE. A escolha dos indicadores do IBGE está fundamentada na necessidade de se utilizar variáveis tecnicamente bem respaldadas, com boa cobertura territorial e populacional, e que representem bem a espacialidade retratada (JANNUZI, 2005). 


\section{Dados de Morbidade}

As variáveis de morbidade utilizadas no trabalho referem-se a um conjunto de doenças que têm sido apresentadas como aquelas que mais preocupam devido à relação da COVID-19 com os casos mais graves e com os óbitos provocados pela doença. A base de dados utilizada foi proveniente do Ministério da Saúde ${ }^{2}$ e se refere ao número de autorização de internação hospitalar - AlH - entre os anos de 2015 e 2019 (BRASIL, 2020b).

As morbidades são apresentadas conforme a Classificação Internacional das doenças (CID-10) descritas pela OMS (WHO, 2019), são elas: Tuberculose (A15, A16, A17, A18 e A19), AIDS (B20, B21, B22, B23, B24), Diabetes (E10, E11, E12, E13, E14), Obesidade (E66) e Asma (J45, J46).

\section{Análises estatísticas}

\section{Análise de Cluster}

Para agrupar os municípios segundo os perfis de vulnerabilidade demográfica e de morbidade à incidência da Covid-19, foram utilizadas a análise de cluster e a análise descritiva dos dados. O uso da análise de cluster teve como objetivo a identificação de padrões de similaridade entre os municípios do NEB, considerando as variáveis utilizadas neste estudo. Segundo Mingoti (2005), esse tipo de análise busca classificar todos os elementos em grupos similares entre si, tentando homogeneizar o grupo e heterogeneizá-los ao mesmo tempo. Na elaboração dos clusters, alguns fatores de risco à doença foram considerados, tais como: número de pessoas com asma, diabetes, AIDS, tuberculose, obesidade, densidade demográfica, taxa de urbanização e percentual de idosos acima de 60 anos.

O resultado está apresentado em 4 grupos de vulnerabilidade (crítica, alta, moderada e baixa), que foram identificados utilizando-se clusterização hierárquica, adotando a distância euclidiana e o método de ligação Ward, com todas as variáveis padronizadas (média 0 e desvio padrão 1). 0 objetivo desse procedimento foi identificar padrões de similaridade entre os municípios, considerando as variáveis envolvidas, e apresentá-las em grupos.

O método hierárquico interliga os objetos (municípios) por suas associações, segundo as variáveis selecionadas, agrupando-os entre si. A técnica consiste em separar os municípios em uma série de agrupamentos sucessivos, produzindo uma representação hierárquica desses agrupamentos. Essa representação (dendrograma) facilita a visualização sobre a formação dos grupos com grau de semelhança entre eles. Os métodos hierárquicos requerem uma matriz contendo as distâncias métricas entre os agrupamentos em cada estágio do algoritmo, e essa matriz é conhecida como matriz de similaridades entre agrupamentos (MINGOTI, 2007; JOHNSON; WICHERN, 2007).

A distância euclidiana é a medida de distância mais frequentemente empregada quando todas as variáveis são quantitativas e é considerada uma medida de dissimilaridade entre dois pontos: $X i$ e $X j$. Essa distância é de fácil implementação e apresenta um tempo computacional menor do que as outras distâncias (apesar de ser sensível a outliers). A operação matemática que define a distância euclidiana pode ser definida como:

$$
d\left[\left(X_{i}, X_{j}\right)\right]=\left[\sum_{k=1}^{p}\left(X_{i, k}-X_{j, k}\right)^{2}\right]^{\frac{1}{2}}
$$

Sendo $X_{i, k}$ e $X_{j, k}$ os elementos a serem comparados. Onde $X_{i} \neq X_{j}=1, \ldots, n$ (número total da amostra), de acordo com a observação da $K$-ésima variável de cada elemento amostral, e $p$ é o número de variáveis. São realizadas comparações entre os dois elementos amostrais para cada variável pertencente ao vetor de observações (MINGOTI, 2005).

Por sua vez, o método de ligação Ward existe para medir a distância entre os agrupamentos e procura por partições que minimizem a perda associada a cada grupo formado, que é encontrada pela diferença

\footnotetext{
2 Os dados foram disponibilizados pelo Ministério da Saúde via solicitação pelo Sistema Eletrônico do Serviço de Informações ao Cidadão - e-SIC, do Governo Federal (protocolo de número 25820002743202043).
} 
entre a soma dos erros quadráticos de cada padrão e a média da partição em que está contido. $\mathrm{O}$ cálculo para encontrar a soma dos erros quadráticos para cada agrupamento é definido como:

$$
E S S_{K}=\sum_{i=1}^{n} x_{i}^{2}-\frac{1}{n}\left(\sum_{i=1}^{n} x_{i}\right)^{2}
$$

Em que:

$k$ é o agrupamento em questão;

$n$ é o número total de objetos do agrupamento $k$;

$x i$ é o $i$-ésimo objeto do agrupamento $k$.

\section{RESULTADOS}

Considerando as variáveis selecionadas, foram descritos os resultados relativos à aplicação da análise de cluster na geração dos grupos (clusters) de vulnerabilidade demográfica e de morbidade à COVID19 para os municípios do NEB e a estatística descritiva dos dados. São apresentadas as características de cada um dos quatro grupos resultantes da estatística utilizada, com apresentação de mapas dos municípios do Nordeste brasileiro, com a localização dos clusters gerados, para melhor ilustrar a distribuição espacial da vulnerabilidade à COVID-19. Por fim, apresenta-se a estatística descritiva das variáveis da pesquisa.

\section{Formação e características dos Clusters de vulnerabilidade}

A classificação dos clusters de vulnerabilidade à COVID-19 é definida através das médias gerais, das variáveis selecionadas de cada grupo/cluster gerado pela análise. A modelagem dos dados gerou um dendrograma (Figura 2), a qual é uma síntese gráfica da análise dos clusters, que agrupa os 1794 municípios do Nordeste Brasileiro, em função do padrão de similaridade das variáveis demográficas e de morbidades apresentadas.

Figura 2- Dendrograma gerado para criação dos clusters

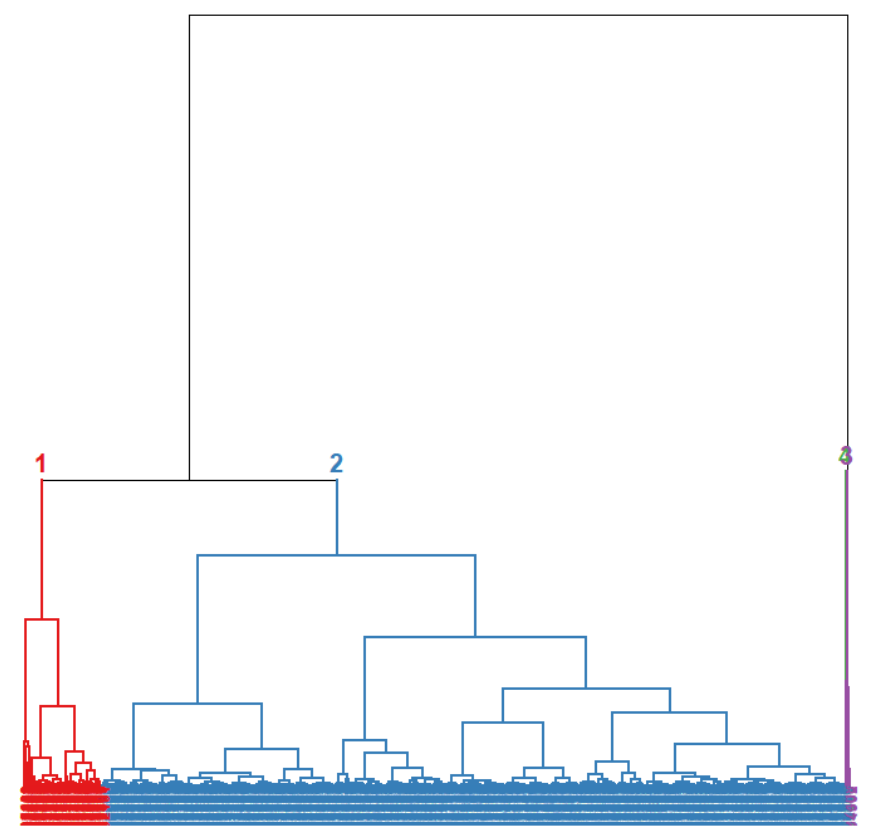

Fonte: Elaborado pelos autores 
Observou-se no dendrograma, figura 2, os quatro clusters formados, em que os elementos amostrais (1794 municípios) são distribuídos horizontalmente, numa ordem relacionada ao contexto do agrupamento. O grupo 2 foi o que apresentou o maior número de municípios (1.617); seguido pelos grupos 1, com 169 municípios; grupo 3, com 7 municípios; e o grupo 4, com apenas 1 município. As médias das variáveis foram utilizadas para a determinação da vulnerabilidade dos municípios à COVID19, sendo: o cluster 1, denominado de vulnerabilidade moderada, o 2, denominado baixa vulnerabilidade, o 3 , denominado alta vulnerabilidade e o cluster 4 , denominado de vulnerabilidade crítica (Tabela 1).

Tabela 1 - Médias das variáveis utilizadas determinantes na constituição dos clusters

\begin{tabular}{|c|c|c|c|c|}
\hline \multirow[t]{2}{*}{ Variáveis } & \multicolumn{4}{|c|}{ Clusters - Vulnerabilidade } \\
\hline & Baixa & Moderada & Alta & Crítica \\
\hline Densidade demográfica (hab/km2) & 56 & 303 & 3.668 & 7.534 \\
\hline Taxa de Urbanização (\%) & 53,3 & 71,2 & 98,3 & 100 \\
\hline População acima de 60 anos (\%) & 11,5 & 10,4 & 9,2 & 11,8 \\
\hline Asma $^{3}$ & 38,5 & 575,8 & $2.914,6$ & 11.057 \\
\hline Obesidade & 0 & 0,6 & 335,4 & 2.262 \\
\hline AIDS & 0,1 & 18,6 & $4.010,7$ & 14.891 \\
\hline Tuberculose & 1 & 25,4 & $1.854,9$ & 5.358 \\
\hline Diabetes & 48,9 & 556,8 & $5.100,1$ & 7.925 \\
\hline
\end{tabular}

Fonte: Elaborado pelos autores

O cluster com "baixa vulnerabilidade" (Figuras 3 e 4) contemplou, predominantemente, municípios que apresentam características de baixa densidade demográfica, baixa urbanização e baixo número de internações correspondentes às doenças. Porém, esse cluster apresentou a segunda maior média no que tange ao percentual de idosos acima de 60 anos.

O grupo considerado de "média vulnerabilidade" agregou, predominantemente, municípios que apresentam médias intermediárias quanto à densidade demográfica, taxa de urbanização e ao número de internações com asma e diabetes. Apresentou também a terceira mais baixa média do percentual de idosos acima de 60 anos e baixas médias de internações de pessoas com obesidade, AIDS e tuberculose.

O cluster de "alta vulnerabilidade" congregou os municípios com alta densidade demográfica, alta taxa de urbanização e alto quantitativo de internações de pessoas com asma, AIDS, tuberculose e diabetes. Esse cluster apresentou o menor percentual de idosos acima de 60 anos e moderado quantitativo de internações por obesidade. Os municípios de São Luís (MA), Teresina (PI), Fortaleza (CE), Natal (RN), João Pessoa (PB), Maceió (AL) e Salvador (BA) formaram juntos o cluster (alta vulnerabilidade) (Figura 3). Esse cluster foi formado pelas capitais dos estados, excluindo-se Recife (PE) e Aracaju (SE), que acabaram sendo incluídas nos clusters de "vulnerabilidade crítica" e "vulnerabilidade moderada", respectivamente.

A ausência de Aracaju (SE), mesmo apresentando alta densidade demográfica e alta taxa de urbanização, na formulação dos grupos de vulnerabilidades alta e crítica, talvez seja explicada pelo baixo percentual de idosos e pela menor quantidade de internações das doenças selecionadas em relação às demais capitais.

O último cluster, denominado de "vulnerabilidade crítica", apresentou as médias mais altas em todas as variáveis, caracterizando-se como um cluster com alta densidade demográfica, alta taxa de urbanização, alto percentual de idosos acima de 60 anos e alto número de internações de pessoas com asma, obesidades, AIDS, tuberculose e diabetes. O município de Recife (PE) compôs isoladamente o cluster de "vulnerabilidade crítica" (Figura 4).

${ }^{3}$ A unidade para as doenças é a quantidade de internações no período de 2015 a 2019.

DOI: http://dx.doi.org/10.14393/Hygeia16055649 $\quad$ Hygeia $\quad$ v.16 $\quad$ p. $232-248,2020$ página 237


Figura 3- Clusters de vulnerabilidade demográfica e de morbidade ao COVID-19 no Nordeste do Brasil

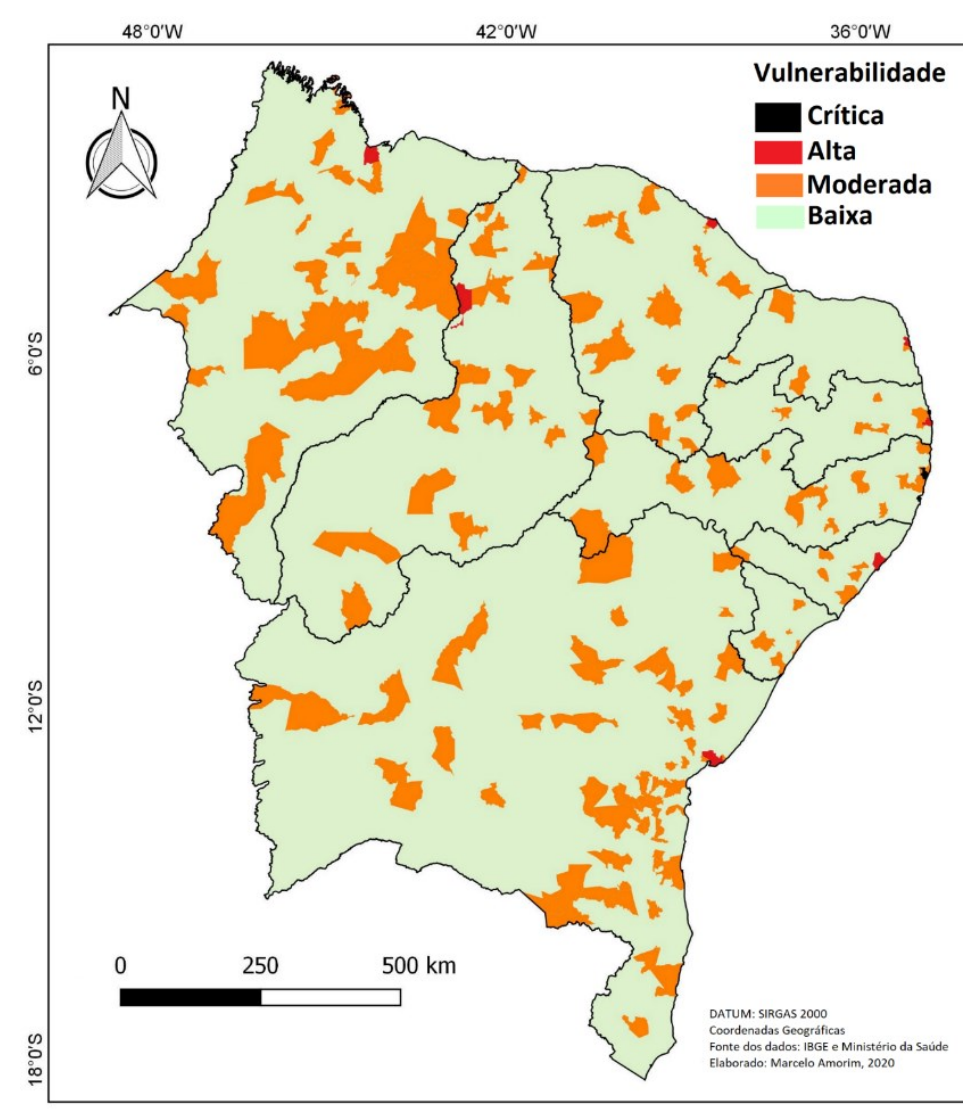

Fonte: Elaborado pelos autores

Figura 4- Clusters de vulnerabilidade demográfica e de morbidade à COVID-19 no Nordeste do Brasil, com destaques para as áreas das capitais

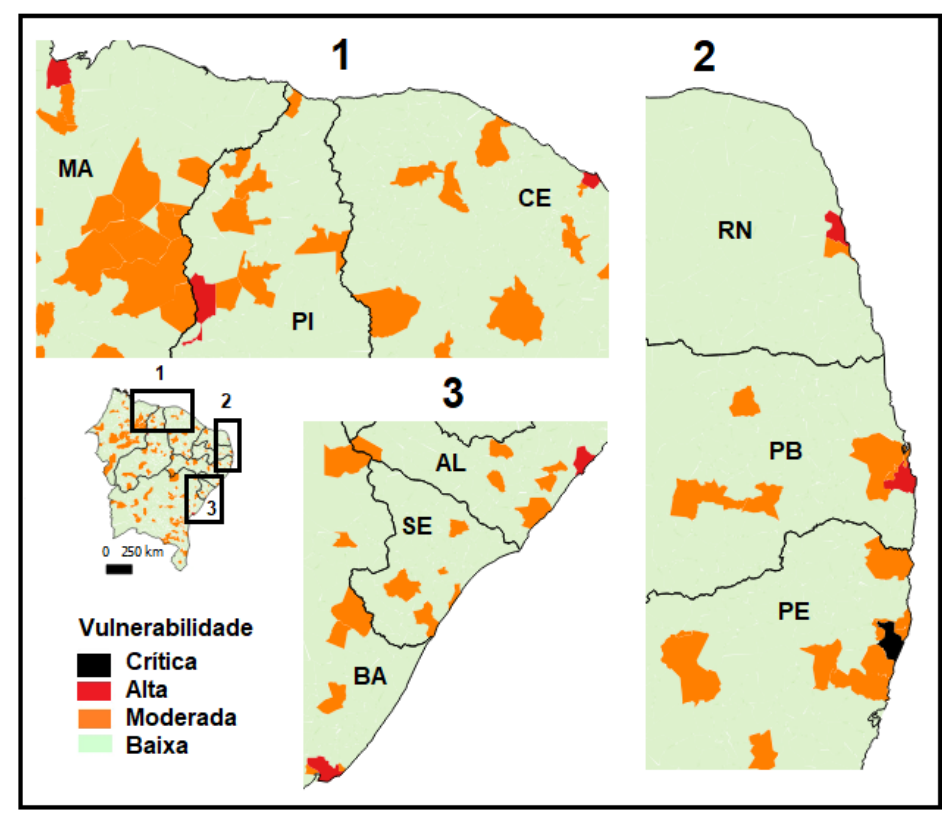

Fonte: Elaborado pelos autores 


\section{Análise descritiva dos dados}

A densidade demográfica entre os clusters variou de 2,47 hab/ $\mathrm{km}^{2}$ a $9.416,33 \mathrm{hab} / \mathrm{km}^{2}$ (Figura 5). 0 cluster denominado de baixa vulnerabilidade apresentou a menor média com $56,13 \mathrm{hab} / \mathrm{km}^{2}$, mas apresentou municípios com mais $1.000 \mathrm{hab} / \mathrm{km}^{2}$, como foram os casos de Nossa Senhora do Socorro (SE) e Juazeiro do Norte (CE). As maiores médias das densidades foram identificadas nos clusters de crítica e de alta vulnerabilidade, com 7.534,17 km² e 3.825,58 hab/ $\mathrm{km}^{2}$, respectivamente, sendo Recife $(\mathrm{PE})$, Fortaleza (CE) e Natal (RN) as maiores densidades. Porém, a maior densidade demográfica foi registrada no município de Olinda (PE), 9.416,33 hab/km², pertencente ao cluster de moderada vulnerabilidade.

Figura 5 - Boxplot da densidade demográfica dos clusters gerados

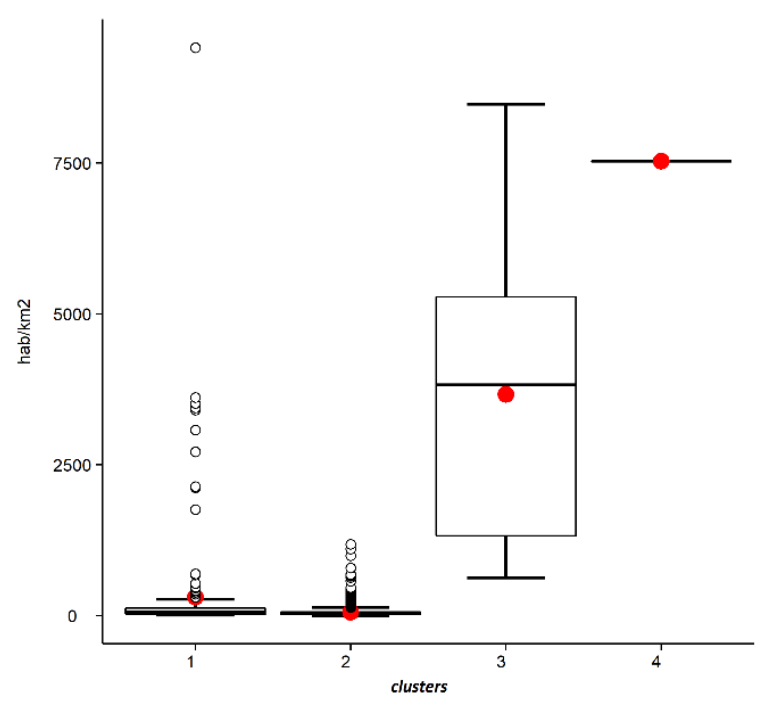

Fonte: Elaborado pelos autores.

A taxa de urbanização variou de $8,32 \%$ a $100 \%$ (Figuras 6 e 7). O cluster de baixa vulnerabilidade teve uma média de urbanização de $53,3 \%$, mas os municípios de Eusébio (CE) e Fernando de Noronha (PE) apresentaram taxa de urbanização de $100 \%$. Os clusters de alta e crítica vulnerabilidade apresentaram médias de $98,3 \%$ e $100 \%$ de população urbana, respectivamente.

Figura 6 - Boxplot da taxa de urbanização dos clusters gerados

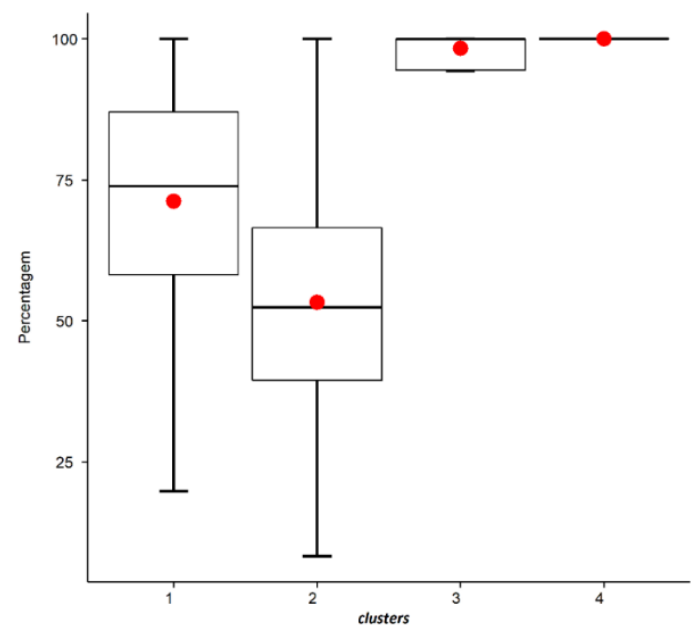

Fonte: Elaborado pelos autores. 
Na Figura 7, que apresenta a espacialização da população urbana no NEB, pode-se observar uma forte presença das baixas taxas de urbanização, o que caracteriza uma importante participação da população rural na região, principalmente no interior. Os dados nos reportam a 1.068 municípios com taxa de urbanização inferior a $60 \%$. Apenas 78 municípios apresentaram população urbana acima de $90 \%$, entre eles, todas as capitais.

Figura 7 - Espacialização da taxa de urbanização nos municípios do NEB

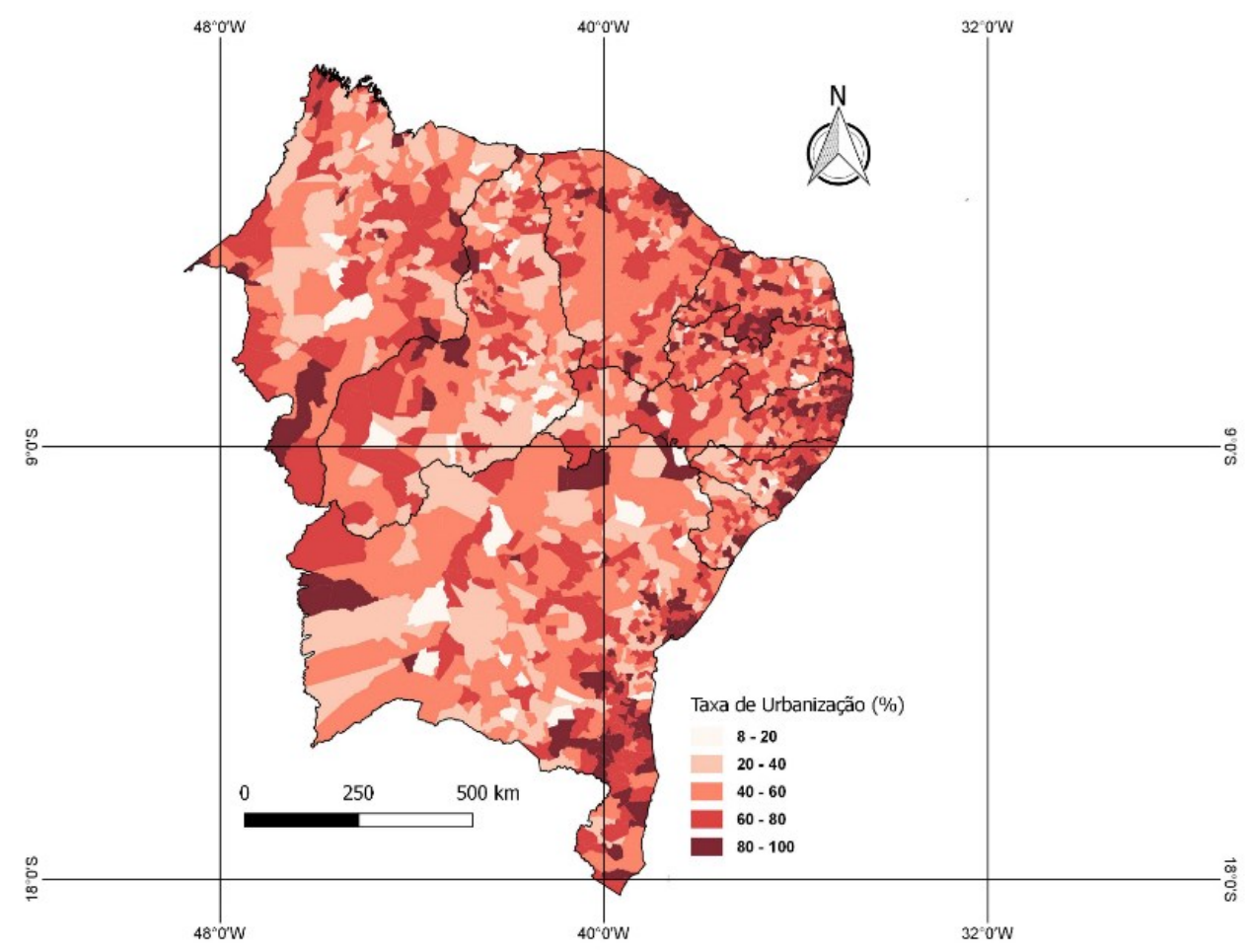

Fonte: Elaborado pelos autores.

Na Figura 8, observa-se que a população de idosos acima de 60 anos variou de $2,6 \%$ a $19,08 \%$ da população municipal. Porém, vale salientar que o percentual da população de idosos em 1.336 municípios do NEB está abaixo da média brasileira que é atualmente de $13 \%$. Tal comparação reforça a premissa de que a região carece de melhores condições socioeconômicas que possam aumentar a expectativa de vida da população. Observa-se que o cluster de baixa vulnerabilidade teve uma média de populção idosa de $11,48 \%$, sendo a segunda maior entre todos os clusters. Os clusters de vulnerabilidade moderada, alta e crítica tiveram médias de idosos de 10,41\%, 9,19\% e 11,82\%, respetivamente.

A espacialização do percentual de idosos acima de 60 anos pode ser verificada na Figura 9. Constatase uma predominância de municípios (1.680) em que o percentual está entre 5 e $15 \%$ da população nessa faixa etária. Observou-se que os estados do Maranhão e de Alagoas apresentam mais de $65 \%$ de seus municípios com um percentual abaixo de $10 \%$ da população acima de 60 anos. Os menores percentuais de idosos acima de 60 anos foram descritos nos municípios de Luís Eduardo Magalhães (BA - 2,6\%), Fernando de Noronha (PE - 3,69\%), Marajá do Sena (MA - 4,53\%) e Nossa Senhora do Socorro (SE - 4,53\%). Os maiores percentuais de idosos foram registrados em Abaíra (BA - 19,08\%), Frei Martinho (PB - 18,82\%), Jussiape (BA - 18,74) e Santa Cruz (PB - 18,64\%). Por sua vez, as capitais que apresentaram os maiores percentuais de idosos foram: Recife (PE - 11,82\%), Natal (RN - 10,44\%), João Pessoa (PB - 10,32\%) e Fortaleza (CE - 9,7\%) . 
Figura 8 - Boxplot do percentual da população com mais de 60 anos por clusters

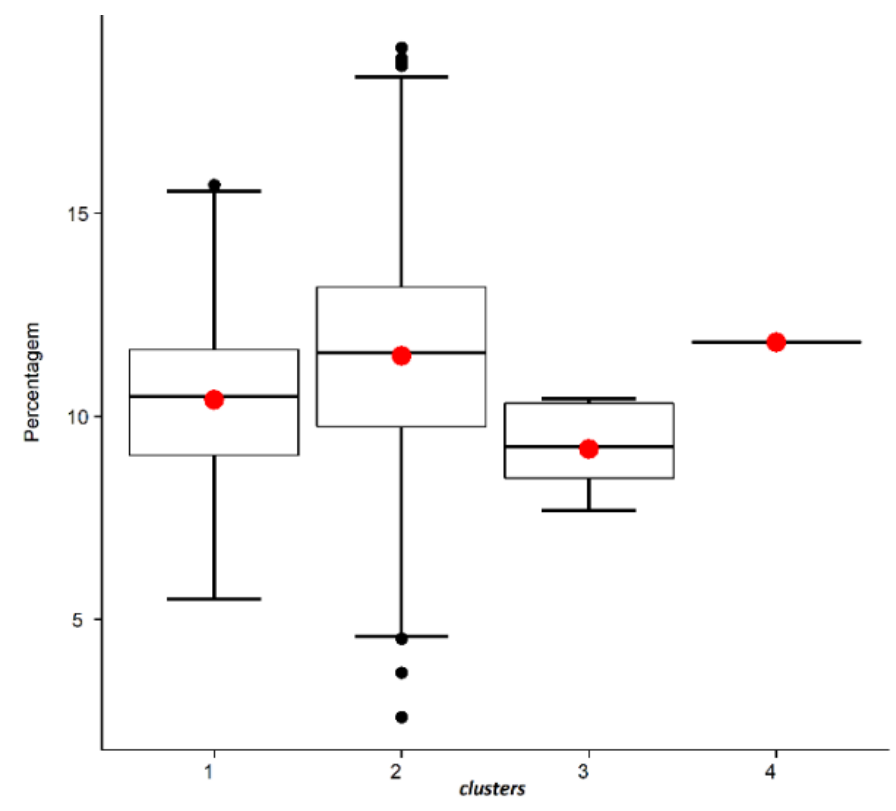

Fonte: Elaborado pelos autores.

Figura 9 - Espacialização do percentual da população com mais de 60 anos nos municípios do NEB

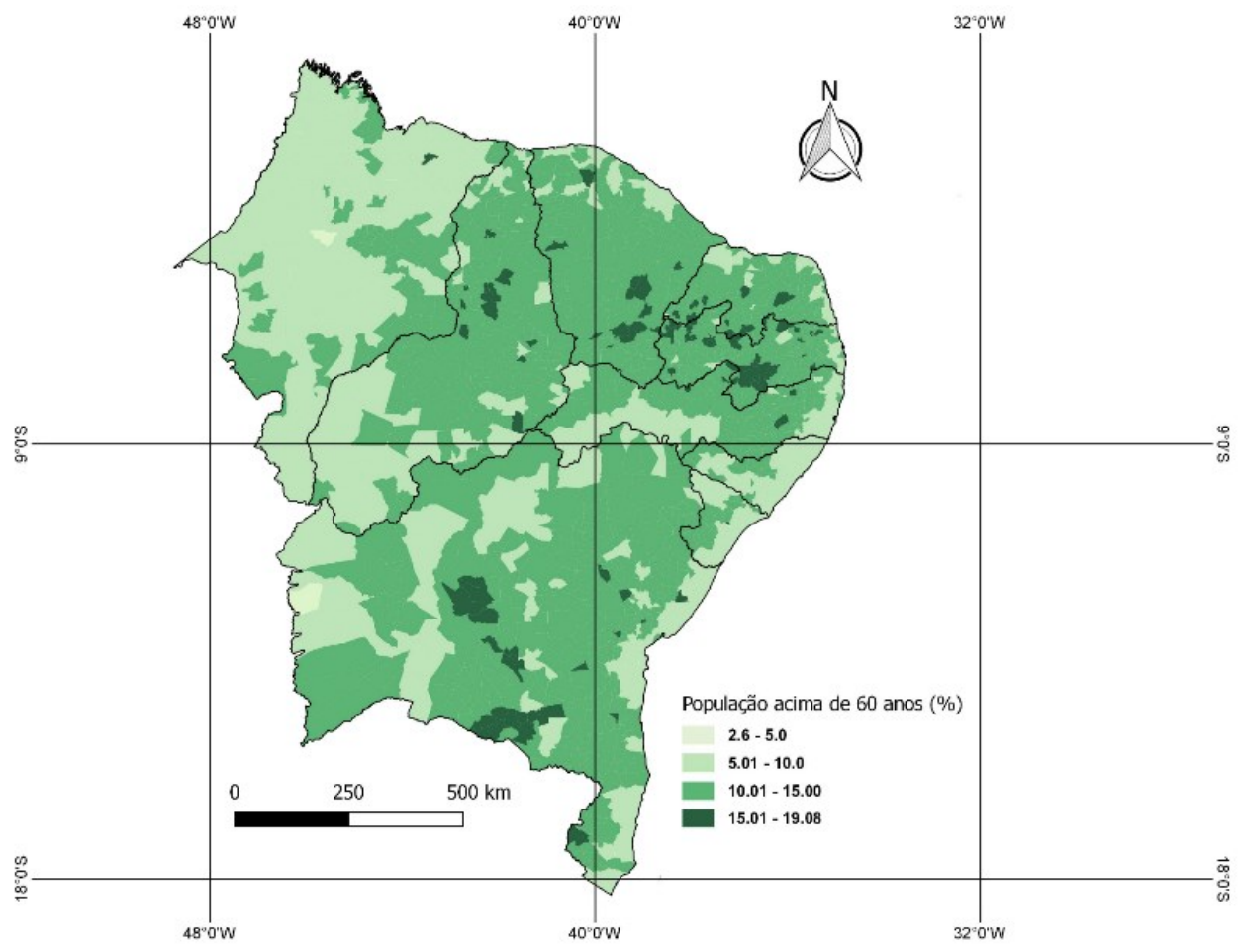

Fonte: Elaborado pelos autores.

A figura 10 refere-se ao total de Internações ocorridas entre os anos de 2015 a 2019, considerando os nove estados do NEB. Quanto ao total de internações, observou-se que a diabetes e a asma foram as mais representativas, e que o quantitativo de internados foi de 482.957, em toda a região, sendo: 
diabetes com 216.717 internações; asma com 191.091 internações; AIDS com 46.223 internações; tuberculose com 24.201 internações; e obesidade com 4.725 internações.

Figura 10 - Total de internações e por doenças selecionadas.

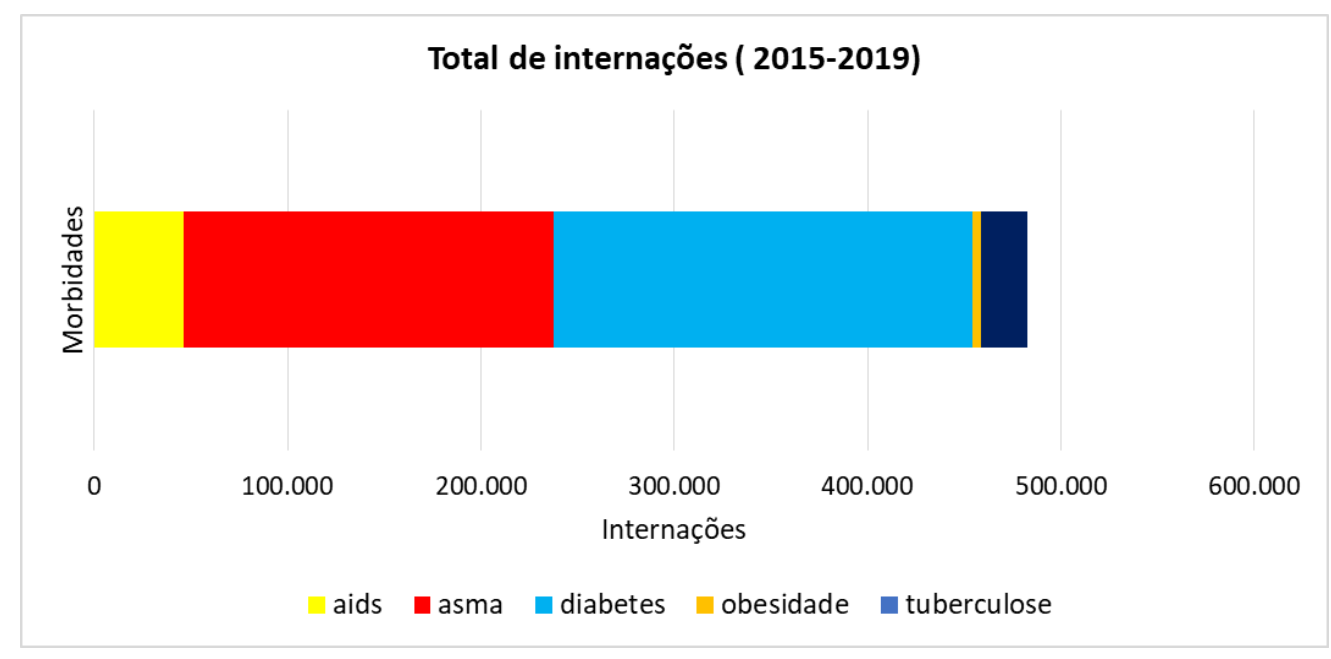

Fonte: Elaborado pelos autores.

Na Figura 11, verifica-se o total de internações por clusters de vulnerabilidade, em que os quantitativos foram: vulnerabilidade moderada com 198.939; seguido por baixa vulnerabilidade com 143.015; alta vulnerabilidade com 99.510; e vulnerabilidade crítica com 41.493.

Figura 11 - Total de internações por doenças selecionadas considerando os cluster de vulnerabilidade

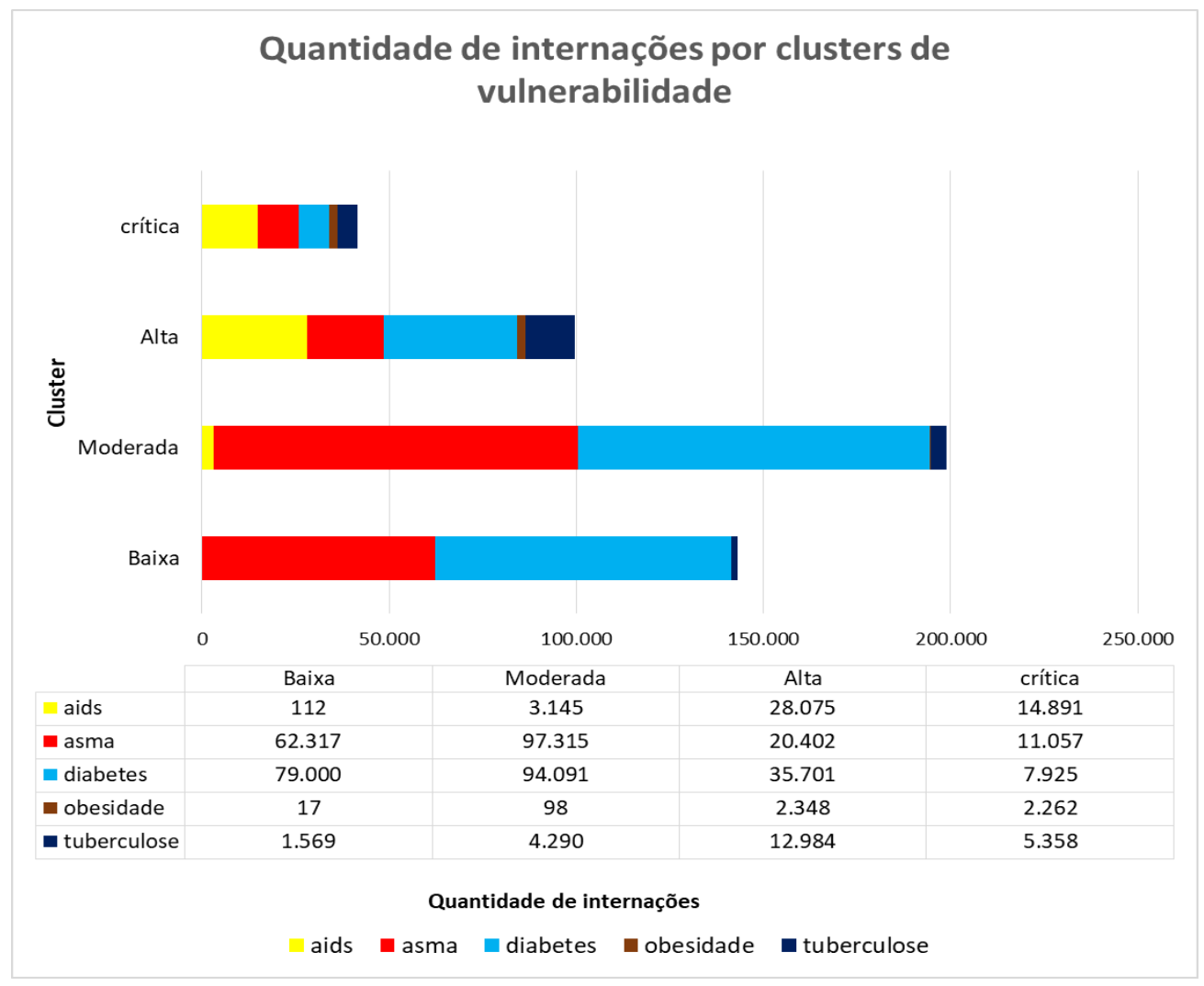

Fonte: Elaborado pelos autores. 
As capitais apresentaram-se com os maiores números de internações referentes às doenças selecionadas, sendo: Recife (PE), com 41.493 internações; Fortaleza (CE), com 28.399; Salvador (BA), com 18.261; e Natal (RN), com 14.520. Constatou-se também que alguns municípios, os quais não são capitais, apresentaram um alto número de internações, como: Campina Grande (PB), com 7.634; São Raimundo Nonato (MA), com 5.124; Vitória da Conquista (BA), com 4.646; Vitória de Santo Antão (PE), com 2.882; e Lagoa de Pedra (MA), com 2.779. Esses municípios, porém, são considerados aqueles que possuem centralidade econômica e de serviços nos seus respectivos estados, o que pode justificar os números.

Os estados da Bahia, Maranhão, Pernambuco e Ceará foram os que registraram os maiores números de internações, considerando as doenças selecionadas. É importante ressaltar que esses estados são os quatro mais populosos da região, o que pode justificar um maior número de internações. Enquanto os estados de Sergipe, Alagoas e Rio Grande do Norte foram aqueles que tiveram menos internações (Figura 12).

Figura 12 - Total de internações por doenças selecionadas considerando os Estados do Nordeste brasileiro

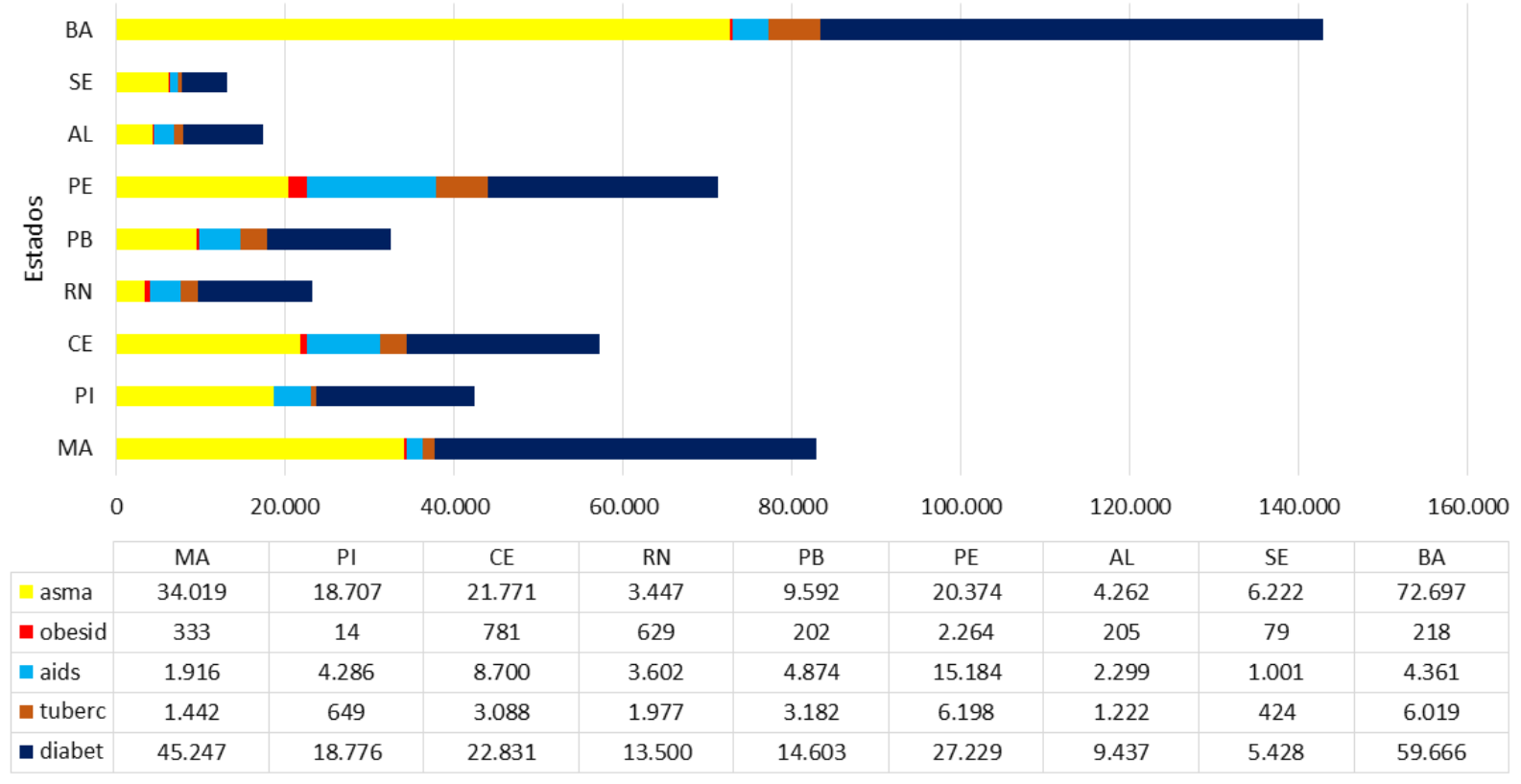

Quantidade de internações

asma $\square$ obesid aids a tuberc $\square$ diabet

Fonte: Elaborado pelos autores.

\section{DISCUSSÃO}

Algumas limitações foram observadas no estudo, tais como: a) a incapacidade de se mensurar quantitativamente as migrações intermunicipais e estaduais, que são capazes de contribuir fortemente com a disseminação do vírus; b) a não identificação, nos dados disponibilizados pelo Ministério da Saúde, da residência do paciente , , havendo a possibilidade de esses pacientes estarem internados em algum município e residir em outro, ou, até mesmo, em outro estado da federação; c) a não consideração do número total de pessoas com as morbidades aqui selecionadas em cada município do Nordeste, pois, não há a disponibilização desses dados, tornando difícil a contabilização dos quantitativos de pessoas acometidas com as morbidades. É importante, entretanto, destacar que as limitações apresentadas não constituíram obstáculos para cumprir a proposta de realização da pesquisa.

A análise de agrupamentos/cluster é considerada uma técnica multivariada e foi utilizada, neste trabalho, com o objetivo de identificar perfis de similaridade entre os municípios do NEB, considerando 
as variáveis apresentadas e, consequentemente, a formação de clusters de vulnerabilidade demográfica e de morbidade à incidência da COVID-19 para toda a Região. A utilização da análise de cluster está de acordo com estudos realizados no Brasil os quais envolveram a relação da análise espacial com ofertas de serviços de saúde pública, dengue, tuberculose e doenças tropicais negligenciadas (SIMÕES et al., 2006; GOLÇALVES, 2012; MELO, 2015; PRADO, 2015).

A análise de cluster pode ser caracterizada como uma técnica estatística que considera um conjunto de informações finita e de dimensão variada, classificando os elementos em grupos homogêneos, o que permite a geração de estruturas que se agregam e, consequentemente, a formação de tipologias analíticas (SIMÕES et al., 2006). A técnica estatística não busca o estabelecimento de relações de causalidade, mas, sim, identificar clusters de semelhanças e diferenças (GONÇALVES, 2012). A análise de cluster ainda pode ser utilizada em estudos epidemiológicos, para analisar uma série de eventos, casos de doença ou fenômenos relacionados à saúde, associando-os com padrões de distribuição espacial e temporal (COHRS et al., 2013).

A vulnerabilidade é um fenômeno dinâmico e complexo em que vários fatores podem contribuir para tornar as pessoas e os territórios vulneráveis diferentemente uns dos outros (WILKISON et al., 2020). Considera-se, então, a vulnerabilidade como o resultado da interação dos perigos de um determinado local com o perfil social das comunidades naquele mesmo local (QUINTÃO, 2017). A vulnerabilidade de uma localidade, em qualquer que seja o fenômeno estudado, está associada a três fatores: risco, exposição e capacidade adaptativa.

O risco está no ar, nas superfícies materiais, é iminente e aflige a todos, que é a presença da circulação viral do SARS-CoV-2. O risco de contágio pelo vírus e, consequentemente, da disseminação da COVID19, é maior, principalmente nas áreas mais povoadas e urbanizadas, onde as atividades comerciais, industriais e de serviços se concentram gerando maiores aglomerações humanas, o que caracteriza a exposição das pessoas ao risco. O processo de interiorização da pandemia nos municípios do NEB, expondo mais pessoas ao risco de contágio, aumenta a preocupação devido às difíceis condições de enfrentamento à doença por parte dos municípios da região (COSTA, OJIMA, 2020). Além disso, as populações de mais idade (KALACHE et al., 2020; WILKISON et al., 2020) - acima de 60 anos - e portadoras de comorbidades preexistentes são consideradas as mais vulneráveis a possíveis agravamentos da doença (CHEN et al., 2020; CDC, 2020; KALACHE et al., 2020; COSTA, OJIMA, 2020; ANVISA, 2020, WILKISON et al., 2020).

A capacidade adaptativa dos municípios do Nordeste do Brasil, em enfrentar a pandemia causada pelo vírus, tem sido revelada diariamente pelos meios de comunicação. Nesses municípios, a falta de infraestrutura hospitalar, a baixa disponibilidade de equipamentos médico-hospitalar e de proteção individual e a escassez de material humano qualificado revelam a falta de prioridade de investimentos na área de saúde ao longo de sucessivos governos.

A visualização dos mapas gerados a partir da plotagem dos clusters e a estatística descritiva apontaram, de forma geral, que houve uma heterogeneidade na distribuição dos clusters nos municípios nordestinos. Porém, há claramente uma concentração dos clusters de alta e crítica vulnerabilidade nas áreas litorâneas, que são os municípios que compreendem as capitais, excetuando-se Aracaju (SE), que foi classificado no cluster de vulnerabilidade moderada. Contatou-se também que a maioria dos municípios polos de cada estado se concentrou no cluster de vulnerabilidade moderada.

A alta e crítica vulnerabilidades das capitais são provavelmente explicadas devido às altas densidades demográficas, altas taxas de urbanização e altos quantitativos de internações de pessoas com as doenças aqui selecionadas. Acredita-se que o número de internações nessas cidades está respaldado na própria estrutura organizacional do sistema de saúde, em um país que centraliza grande parte de procedimentos nas cidades principais. A presença de um percentual significante de idosos acima de 60 anos também contribuiu para uma maior vulnerabilidade desses municípios.

A análise da densidade demográfica de cada município do NEB, como variável deste estudo, fundamenta-se na premissa de que é mais importante analisar o recorte espacial onde efetivamente as pessoas habitam do que simplesmente um recorte político-administrativo (OJIMA, 2020). Os resultados mostraram que a maioria dos municípios (1.494) da região apresentam uma densidade demográfica abaixo de 100 hab $/ \mathrm{km}^{2}$, e apenas 20 municípios apresentam densidades demográficas acima de 1.000 $\mathrm{hab} / \mathrm{km}^{2}$. 
Mesmo assim, é importante ressaltar que os municípios que apresentam baixa densidade demográfica não estão isentos de vivenciar índices elevados de contágio da doença, uma vez que a escala de análise pode gerar uma falsa sensação de que há uma boa distância média entre as pessoas, o que pode acarretar relaxamento com as medidas de prevenção, principalmente os relativos a deslocamentos das pessoas no espaço, na perspectiva de resolverem suas demandas pessoais (COSTA; OJIMA, 2020).

Acredita-se que o distanciamento físico das pessoas é a melhor forma de conter a propagação viral, porém ressalta-se que cidades de menor densidade não são menos vulneráveis à pandemia (PAFKA, 2020). Ainda segundo Pafka (2020), a doença é transmitida principalmente por meio de contato próximo e prolongado de pessoas em locais fechados, o que não isenta os municípios de menor densidade demográfica de se tornarem focos da doença.

Os idosos são considerados um dos grupos demográficos de maior preocupação em relação à COVID19 (ANVISA, 2020; CHEN et al., 2020; CDC, 2020; KALACHE et al., 2020; OPAS, 2020). Neste estudo, constatou-se que os municípios que apresentaram os maiores percentuais de idosos (acima de 13\%) foram classificados nos clusters de baixa e média vulnerabilidades. São municípios que apresentam uma população absoluta entre 1.771 a 40.721 habitantes.

É importante ressaltar que as médias de percentual de idosos, entre os clusters de vulnerabilidade, variaram pouquíssimo, e que um maior percentual de idosos nos municípios de baixa vulnerabilidade pode, inclusive, se analisado separadamente, aumentar a atenção quanto às possíveis consequências da disseminação da doença para a população desses municípios, que geralmente têm pouca estrutura hospitalar. Surge, então, a necessidade de se verificar o percentual de idosos em relação ao total da população de um determinado município, quando se pensar em algum tipo de política de distanciamento e isolamento social ou no relaxamento destas práticas.

A taxa de urbanização dos municípios nordestinos é muito variada, a saber: 1.035 municípios apresentam urbanização abaixo de $50 \%$ e 440 municípios têm taxas acima de $70 \%$, tendo as capitais valores que variam entre $94,27 \%$ e $100 \%$. Porém, chama a atenção que, mesmo tendo uma grande quantidade de municípios com pessoas vivendo em áreas não urbanas - e levando-se em consideração que isso poderia minimizar os efeitos da propagação da doença por estarem fora dos maiores aglomerados humanos - é importante ressaltar que não se pode relaxar as medidas de prevenção.

Os deslocamentos cotidianos das pessoas entre as áreas rurais e urbanas nos municípios do NEB para resolverem suas pendências de sustento, de família, de saúde ou de outras necessidades - podem influenciar numa maior exposição da população ao contágio pela doença, aumentando a interiorização do surto.

Um estudo de Wilkison et al. (2020), que menciona o surto de Ébola na África Ocidental, ressalta a importância de um maior controle do movimento de pessoas entre as localidades rurais e urbanas, como estratégia de minimizar a propagação da COVID-19, e afirma que restringir a mobilidade das pessoas tem sido uma forma de difícil gerenciamento e ineficácia, se não forem consideradas as necessidades de subsistência da população.

Os resultados mostraram que, das doenças selecionadas, a diabetes foi a que teve o maior número de internações, considerando a somatória das internações entre os anos de 2015 a 2019. É preciso destacar que pessoas com diabetes não parecem apresentar maior risco de contrair a COVID-19, porém, quando infectadas com o vírus, as pessoas com essa doença têm maior possibilidade de complicações graves e de morte por COVID-19 (OPAS, 2020; SILVA JÚNIOR et al., 2020). Ainda conforme os autores, o risco de agravamento da doença tem aumentado para os portadores de diabetes 1 e 2 (DM1 e DM2) e o agravamento se relaciona à maior idade, tempo de duração da doença, controle metabólico, hipertensão arterial e doença renal.

Destaca-se também que portadores de diabetes do tipo 1 podem ter outras doenças imunossupressoras, o que pode gerar um maior comprometimento imunológico (SILVA JÚNIOR et al., 2020). Para a Sociedade Brasileira de Diabetes (SBD, 2020) e para a Juvenile Diabetes Research Foundation (JDRF, 2020), as pessoas de maior risco são aquelas com níveis elevados permanentemente de açúcar no sangue e com outra doença preexistente crônica, principalmente as cardíacas e pulmonares.

A asma foi a segunda causa de internações entre as doenças selecionadas, e a disseminação da COVID-19 tem preocupado os portadores de asma, principalmente quanto à continuidade ou não do tratamento. Conforme a Sociedade Brasileira de Pneumologia e Tisiologia, os asmáticos fazem parte

DOI: http://dx.doi.org/10.14393/Hygeia16055649 $\quad$ Hygeia $\quad$ v.16 $\quad$ p. $232-248,2020$ página 245


do grupo de risco, com possíveis complicações em relação à COVID-19, e ela sugere que os portadores de asma, em particular os mais graves, sigam as recomendações que são orientadas aos portadores de doenças crônicas (SBPT, 2020).

Os asmáticos são vulneráveis à pandemia, pois os aspectos clínicos da COVID-19 são variados e se apresentam através de infecções assintomáticas e de infecções do aparelho respiratório que evoluem da forma mais leve até a mais grave, com insuficiência respiratória, podendo evoluir até o óbito (ZHOU et al., 2020).

Além disso, a disfunção orgânica tem se apresentado como uma das características dos pacientes da COVID-19 que, entre os sinais, aparecem à síndrome respiratória aguda, lesões cardíacas e renal agudas (WANG et al., 2020). Assim, pacientes com asma, que é uma doença inflamatória crônica do trato respiratório, devem ter uma atenção redobrada em relação aos desdobramentos da COVID-19, até que se tenha um tratamento ou vacina eficazes.

\section{CONCLUSÕES}

O mundo tem vivenciado uma grave pandemia provocada pela COVID-19. A importância deste estudo fundamenta-se na perspectiva de se criar perfis de vulnerabilidade demográfica e de morbidade à incidência da COVID-19 para os municípios do Nordeste do Brasil (NEB).

Utilizou-se da Análise de Cluster, com o objetivo de identificar possíveis padrões de similaridade entre os municípios do NEB, considerando as variáveis demográficas e de morbidade utilizadas neste estudo. As médias obtidas de cada variável foram utilizadas para a determinação da vulnerabilidade dos municípios à COVID-19, sendo os resultados apresentados em quatro clusters, a saber: vulnerabilidade baixa, moderada, alta e crítica.

Nos resultados deste trabalho, observou-se uma heterogeneidade na distribuição dos clusters nos municípios nordestinos, com uma concentração dos clusters de alta e crítica vulnerabilidade nas áreas litorâneas, que são os municípios que compreendem as capitais, excetuando-se Aracaju (SE), classificado no cluster de vulnerabilidade moderada. Constatou-se também que a maioria dos municípios polos de cada estado se concentrou no cluster de vulnerabilidade moderada.

A formação dos clusters variou conforme as similaridades das variáveis apresentadas por cada município, onde a "vulnerabilidade crítica" apresentou alta densidade demográfica, alta taxa de urbanização, alto percentual de idosos acima de 60 anos e alto número de internações de pessoas com asma, obesidades, AIDS, tuberculose e diabetes. No outro extremo, a "vulnerabilidade baixa" foi constituída, em sua maioria, por municípios com baixa densidade demográfica, baixa urbanização e baixo número de internações correspondentes às doenças selecionadas. Neste cluster, o percentual de idosos acima de 60 anos foi o segundo mais significativo entre os clusters.

Acredita-se que a dinâmica (epidemiológica e espacial de propagação e seus efeitos) da COVID-19 seja um processo extremamente complexo, que exige estudos complementares, inclusive com a composição de outras variáveis. Porém, compreender os condicionantes demográficos e de morbidades associados ao COVID-19 é elemento fundamental para possibilitar novos conhecimentos que possam contribuir nas tomadas de decisões por parte dos agentes públicos responsáveis pelas políticas públicas de saúde e sanitária de cada município. Além disso - e o mais importante, pode-se reduzir o número de vítimas da doença, principalmente em relação à fase mais aguda, assim como os óbitos.

\section{REFERÊNCIAS}

AGÊNCIA NACIONAL DE VIGILÂNCIA SANITÁRIA - ANVISA. Orientações para a prevenção e o controle de infecções pelo novo coronavírus (SARS-COV-2) em instituições de longa permanência para idosos (ILPI). Nota técnica GVIMS/GGTES/ANVISA No. 05/2020. Brasília, 2020.

AHMED F.; AHMED N.; PISSARIDES, C.; STIGLITZ, J. Why inequality could spread COVID-19. Lancet Public Health. April 2, 2020. https://doi.org/10.1016/S2468-2667(20)30085-2

BRASIL. Ministério da Saúde. COVID19: Painel Coronavírus. 2020a. Disponível em: <https://covid.saude.gov.br/>. Acesso em: 08 abr.2020.

Ministério da Saúde. Coordenação Geral de Sistemas de Informação. Sistema de Informações Hospitalares. Número de Autorização de Internação Hospitalar: 2015-2019. Brasília, 2020b. 
CHEN, Nanshan; ZHOU, Min; DONG, Xuan; QU, Jieming; GONG, Fengyun; HAN, Yang; QIU; Yang et al. Epidemiological and clinical characteristics of 99 cases of 2019 novel coronavirus pneumonia in Wuhan, China: a descriptive study. The Lancet. ed. 395, p. 507-513, feb 15, 2020. https://doi.org/10.1016/S0140$\underline{6736(20) 30211-7}$

COHRS, F.M; SOUSA, F.S; TENÓRIO, J.M; RAMOS, L.R; PISA, I.T. Application of Cluster Analysis in integrated data of a prospective study: project epidoso as a scenario. J. Health Inform: 5(1):17-22, 2013.

COSTA, P.V.M.; OJIMA, R. A vulnerabilidade à Covid-19 no semiárido nordestino: metade dos municípios já tem casos confirmados. Disponível em: https://demografiaufrn.net/2020/05/14/covid-nosemiarido-nordestino/>. Acesso em: 17 mai. 2020.

DELATORRE, Edson; MIR, Daiana; GRÄF, Tiago; BELLO, Gonzalo. Tracking the onset date of the community spread of SARS-CoV-2 in Western Countries. [Submitted]. Mem Inst Oswaldo Cruz. E-pub: 24 Apr 2020. https://doi.org/10.1590/0074-02760200183

EMAMI, Amir; JAVANMARDI, Fatemeh; PIRBONYEH, Neda; AKBARI Ali. Prevalence of Underlying Diseases in Hospitalized Patients with COVID-19: a Systematic Review and Meta-Analysis. Arch Acad Emerg Med. 8(1):e35, mar, 2020.

GONCALVES, M.J.F. Avaliação de Programa de Saúde: O Programa Nacional de Controle de Tuberculose no Brasil. Sau. \& Transf. Soc., ISSN 2178-7085, Florianópolis, v.3, n.1, p.13-17, 2012.

INSTITUTO BRASILEIRO DE GEOGRAFIA E ESTATÍSTICA - IBGE. Projeções da População. Disponível em: $\quad<$ https://www.ibge.gov.br/estatisticas/sociais/populacao/9109-projecao-da-populacao.html?=\&t= resultados>. Acesso em: 28 abr. 2020.

JANNUZZI, P.M. Indicadores para diagnóstico, monitoramento e avaliação de programas sociais no Brasil. Brasília: Revista do Serviço Público, n. 56, 2005. https://doi.org/10.21874/rsp.v56i2.222

JOHNSON, R.A; WICHERN D.W. Applied Multivariate Statisitical Analysis, sixth ed. Upper Saddle River, NJ: Pearson/Prentice Hall, 2007.

JUVENILE DIABETES RESEARCH FOUNDATION (JDRF) [internet]. T1D and Coronavirus: What You Need to Know. Disponível em: <https://www.jdrf.org/coronavirus/>. Acesso em: 05 jun. 2020.

KALACHE, A.; SILVA, A.; RAMOS, L.; LOUVISON, M.; VERAS R.; LIMA, K. Pandemia da Covid-19 e um Brasil de desigualdades: populações vulneráveis e o risco de um genocídio relacionado à idade. Disponível em: <https://www.abrasco.org.br/site/gtenvelhecimentoesaudecoletiva/2020/03/31 /pandemiado-covid-19-e-um-brasil-de-desigualdades-populacoes-vulneraveis-e-o-risco-de-umgenocidio-relacionadoa-idade/>. Acesso em: 19 mai. 2020.

LIU, Y.; GAYLE, A.A.; WILDER-SMITH, A.; ROCKLÖV, J. The reproductive number of COVID-19 is higher compared to SARS coronavirus. J Travel Med., 27(2). P. 30-31. 2020. https://doi.org/10.1093/itm/taaa021

LU, Roujian; ZHAO, Xiang; LI, Juan; NIU, Peihua; YANG, Bo; WU, Honglong; WANG, Wenling et al. Genomic characterisation and epidemiology of 2019 novel coronavirus: implications for virus origins and receptor binding. The Lancet. v. 395, Feb 22, P. 565-574, 2020. https://doi.org/10.1016/S0140-6736(19)33096-X

MELO, F.R.M. Mortalidade relacionada às doenças tropicais negligenciadas no Brasil, 2000-2011: magnitude, padrões espaço-temporais e fatores associados. 2015. Tese (Doutorado em Saúde Coletiva). Universidade Federal do Ceará, Fortaleza - CE, 2015.

MINGOTI, S.A. Análise de Dados Através de Métodos de Estatística Multivariada: uma abordagem aplicada. Belo Horizonte: Editora UFMG, 2005.

Editora UFMG, $1^{\mathrm{a}}$ reimpressão, 2007.

OJIMA, R. O que nos diz a densidade demográfica para analisar a covid-19 no estado do Amazonas?. Disponível em: <https://demografiaufrn.net/2020/04/14/o-que-nos-diz-a-densidade-demografica-paraanalisar-a-covid-19-no-estado-do-amazonas/>. Acesso em: 15 mai. 2020.

ORGANIZAÇÃO PAN-AMERICANA DE SAÚDE (OPAS). Folha informativa - COVID-19 (doença causada pelo novo coronavírus). Disponível em: $<$ https://www.paho.org/bra/index .php?option=com_content\&view=article\&id=6101:covid19\&ltemid=875>. Acesso em: 23 mai. 2020. 
PAFKA, E. As coronavirus forces us to keep our distance, city density matters less than internal density. Disponível em: <https://theconversation.com/as-coronavirus-forces-us-to-keep-ourdistance-city-density-matters-less-than-internal-density-137790>. Acesso em: 19 mai. 2020.

PRADO, B.Q.M. Análise de agrupamentos das taxas de incidência de dengue nos estados brasileiros. Universidade Federal de Uberlândia. Uberlândia - MG, 2015.

QUINTÃO, A.F; BRITO I.; OLIVEIRA F.; MADUREIRA A.P.; CONFALONIERI, U. Social, Environmental, and Health Vulnerability to Climate Change: The Case of the Municipalities of Minas Gerais, Brazil. Journal of Environmental and Public Health. v. 2017, Article ID 2821343, 8 pages, 2017. https://doi.org/10.1155/2017/2821343

SILVA JÚNIOR, W.S; PEDROSA, H.; FERRAZ, C.; GUERRA, M.; MEIRELLES, R. Diabetes e Pandemia de Covid-19. Sociedade Brasileira de Endocrinologia e Metabologia. Disponível em: $<$ https://www.endocrino.org.br/diabetes-e-pandemia-de-covid-19/>. Acesso em 05 jun. 2020.

SIMÕES, R.; GUIMARÃES, C.; GODOY, N.; VELLOSO, T.; ARAÚJO, T.; GALINARI, R. et al. Rede Urbana da oferta de serviços de saúde: uma análise de clusters espaciais para minas gerais. In: XIV ENCONTRO NACIONAL DE ESTUDOS POPULACIONAIS, ABEP, Caxambú-MG, 2004.

SOCIEDADE BRASILEIRA DE DIABETES (SBD). Notas de esclarecimentos da Sociedade Brasileira de Diabetes sobre o coranavírus (COVID-19). Disponível em :<https://www.diabetes.org.br/publico/notasde-esclarecimentos-da-sociedade-brasileira-de-diabetes-sobre-o-coronavirus-covid-19/2061-parceria-jdrfsbd-t1d-and-coronavirus-what-you-need-to-know-diabetes-tipo-1-e-coronavirus-o-que-voce-precisasaber>. Acesso em: 05 jun. 2020.

SOCIEDADE BRASILEIRA DE PNEUMOLOGIA E TISIOLOGIA (SBPT). Posicionamento da Sociedade Brasileira de Pneumologia e Tisiologia sobre o manuseio da asma em vigência da pandemia de coronavírus. Disponível em: <https://sbpt.org.br/portal/sbpt-asma-covid-24-03/>. Acesso em: 05 jun. 2020.

SUN, Zhong; THILAKAVATHY, Karuppiah; KUMAR, S. Suresh; HE, Guozhong; SHI, V. Liu. Potential Factors Influencing Repeated SARS Outbreaks in China. Int. J. Environ. Res. Public Health. 17, 1633; 2020. https://doi.org/10.3390/ijerph17051633

UNITED STATES CENTER FOR DISEASE CONTROL AND PREVENTION (CDC). Types of Human Coronavirus. Disponível em: <https://www.cdc.gov/coronavirus/types.html>. Acesso em: 06 abr. 2020.

WANG, D.; HU, B.; HU, C. et al. Clinical Characteristics of 138 Hospitalized Patients with2019 Novel Coronavirus-Infected Pneumonia in Wuhan, China. JAMA. Published online February 07, 2020. https://doi.org/10.1001/jama.2020.1585

WILKINSON, A.; ALI, H.; BEDFORD, J.; BOONYABANCHA, S.; CONNOLLY, C.; CONTEH, A.; DEAN, L. Local response in health emergencies: key considerations for addressing the COVID-19 pandemic in informal urban. International Institute for Environment and Development. (IIED), Brighton-UK. Environment \& Urbanization, 2020. https://doi.org/10.1177/0956247820922843

WORLD HEALTH ORGANIZATION (WHO) [internet]. International Statistical Classification of Diseases and Related Health Problems 10th Revision. 2019. Disponivel em:< https://icd.who.int/browse10/2019/en\#>. Acesso em: 21 jul. 2020.

[internet]. Coronavirus disease (COVID-19) Pandemic. 2020. Disponível em: <https://www.who.int/emergencies/diseases/novel-coronavirus-2019>. Acesso em: 08 abr. 2020.

XU, Rui-Heng; HE, Jian-Feng; EVANS, Meirion R.; PENG, Guo-Wen; FIELD, Hume E.; YU, De-Wen; LEE, Chin-Kei et al. Epidemiologic Clues to SARS Origin in China. Emerging Infectious Diseases. v. 10, n. 6, jun, 2004. https://doi.org/10.3201/eid1006.030852

ZHOU, F.; YU, T.; DU R.; FAN, G.; LIU, Y.; LIU, Z.; XIANG, J. et al. Clinical course and risk factors for mortality of adult inpatients with COVID-19 in Wuhan, China: a retrospective cohort study. The Lancet. v 395: 28 mar, 1054-62, 2020. https://doi.org/10.1016/S0140-6736(20)30566-3 